JOURNAL OF

SYNCHROTRON

RADIATION

ISSN 1600-5775

\section{Beam-induced redox transformation of arsenic during As $K$-edge XAS measurements: availability of reducing or oxidizing agents and As speciation}

\author{
Young-Soo Han, ${ }^{a}$ Hoon Young Jeong, ${ }^{b *}$ Sung Pil Hyun, ${ }^{a}$ Kim F. Hayes ${ }^{c}$ and \\ Chul-Min Chon ${ }^{\mathrm{a}}$
}

Received 28 September 2017

Accepted 12 February 2018

Edited by R. W. Strange, University of Essex, UK

Keywords: X-ray absorption spectroscopy; photocatalytic transformation; mackinawite; arsenic; linear combination fitting.

Supporting information: this article has supporting information at journals.iucr.org/s

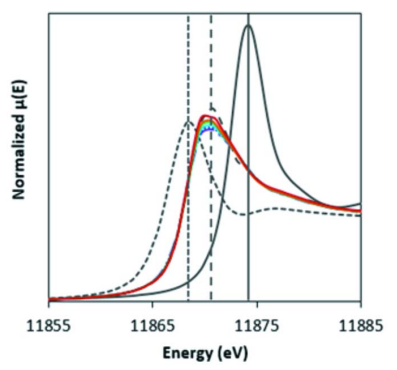

(C) 2018 International Union of Crystallography
${ }^{a}$ Geologic Environment Division, Korea Institute of Geoscience and Mineral Resources, Deajeon 34132, Republic of Korea, 'bepartment of Geological Sciences, Pusan Natinal University, Busan 46241, Republic of Korea, and ' Department of Civil and Environmental Engineering, University of Michigan, Ann Arbor, MI 48105, USA. *Correspondence e-mail: hjeong@pusan.ac.kr

During X-ray absorption spectroscopy (XAS) measurements of arsenic (As), beam-induced redox transformation is often observed. In this study, the As species immobilized by poorly crystallized mackinawite (FeS) was assessed for the susceptibility to beam-induced redox reactions as a function of sample The beam-induced oxidation of reduced As species was found to be mediated by the atmospheric $\mathrm{O}_{2}$ and the oxidation products of $\mathrm{FeS}$ [e.g. $\mathrm{Fe}$ (III) (oxyhydr)oxides and intermediate sulfurs]. Regardless of the redox state of FeS, both arsenic sulfide and surface-complexed As(III) readily underwent the photo-oxidation upon exposure to the atmospheric $\mathrm{O}_{2}$ during XAS measurements. With strict $\mathrm{O}_{2}$ exclusion, however, both $\mathrm{As}(0)$ and arsenic sulfide were less prone to the photo-oxidation by $\mathrm{Fe}$ (III) (oxyhydr)oxides than $\mathrm{NaAsO}_{2}$ and/ or surface-complexed As(III). In case of unaerated As(V)-reacted FeS samples, surface-complexed As(V) was photocatalytically reduced during XAS measurements, but arsenic sulfide did not undergo the photo-reduction.

\section{Introduction}

X-ray absorption spectroscopy (XAS) is useful in examining the speciation of arsenic. This is particularly true if As contents in samples are below the detection limit of conventional X-ray diffraction (XRD), or if the As species are poorly crystalline or amorphous in nature. Foster \& Kim (2014) reviewed XAS studies in which the local coordination structures of As were determined from a range of samples: model systems; naturally occurring As-bearing biogenic minerals or synthetic analogs; rocks, related soils and rock-forming fluids; ores, mine wastes and mining-impacted sites; and floodplain and aquatic sediments. It has been recognized that the beaminduced redox transformation of As may pose a great challenge in the accurate determination of As speciation by XAS analyses (Bostick \& Fendorf, 2003; Bostick et al., 2003; Charlet et al., 2011; Lee et al., 2011; Ona-Nguema et al., 2005). Even inside controlled anoxic sample chambers, the As(III) species sorbed by $\mathrm{PbS}$ and $\mathrm{FeS}_{2}$ were found to undergo beam-induced oxidation to $\mathrm{As}(\mathrm{V})$ possibly due to oxidized sulfurs during XAS measurements (Bostick \& Fendorf, 2003; Bostick et al., 2003). Also, other oxidants such as iron or manganese oxides often caused kinetically limited oxidation under X-ray beam radiation (Keune et al., 2015; Morin et al., 2008).

Beam-induced reduction of As has also been reported in previous XAS studies. For example, the photocatalytic reduction of $\mathrm{As}(\mathrm{V})$ to $\mathrm{As}(\mathrm{III})$ in taxidermed animal hair properties including the redox state of FeS and the solid-phase As speciation. 
samples occurred so fast that the initially added $\operatorname{As}(\mathrm{V})$ was completely reduced within one regular XANES scan time (Kempson et al., 2009). The photo-reduction of $\mathrm{As}(\mathrm{V})$ to As(III) was also observed during XANES measurements of rice grain samples, with organic matter acting as electron donors (Lombi et al., 2011; Smith et al., 2009). The photocatalytic reduction during XANES measurements have also been observed for other elements. The reduction of $\mathrm{Cu}$ (II) to $\mathrm{Cu}(\mathrm{I})$ or $\mathrm{Cu}(0)$ was facilitated by sample exposures to X-ray beams (Gruenert et al., 1994; Luo et al., 2014; Mavrogenes et al., 2002; Su et al., 2011; Yang et al., 2011). The photo-reduction of ionic to metallic $\mathrm{Au}$ was also reported during XAS measurements (Ohkubo et al., 2014). Furthermore, the photocatalytic reduction of oxyanions such as selenite and uranium(VI) was observed even at cryogenic temperatures (Alessi et al., 2013; George et al., 2012). In most of the aforementioned examples, reduced sulfurs or organic matters were suggested as electron donors for mediating the photoreduction.

During XAS measurements of metalloproteins, George $e t$ al. (2012) identified several variables affecting the beaminduced redox transformation: beam intensity and exposure time, sample translocation, collection temperature, the presence of free radical scavengers, and the freeze-drying of biological samples. Of these variables, Alessi et al. (2013) found that the beam intensity, the photon flux per unit area, was critical in determining the beam-induced oxidation of U(IV). Consistently, Charlet et al. (2011) also noticed that beam-catalyzed redox transformation became more pronounced under a focused beam on micrometer or nanometer scales. In efforts to reduce beam exposure time, a quick-scanning XAS (Q-XAS) on sub-second time scales has been employed for As analysis (Bhandari et al., 2011, 2012; Ginder-Vogel et al., 2009).

Previous studies have been largely focused on the effects of beam intensity, beam exposure time and measurement conditions (e.g. collection temperature or atmospheric mood). In contrast, this study aimed to evaluate the effect of sample properties on the susceptibility to beam-induced As redox transformation during XAS measurements, with the focus on the availability of reducing or oxidizing agents and the As speciation. In the present study, poorly crystallized mackinawite (FeS) was selected as a sorbent for As(III) and As(V) due to its great sorption capacity, high reducing capability and fast oxidation kinetics under aerobic conditions. For XAS measurements, As(III)- or As(V)-reacted FeS samples were prepared at different $\mathrm{pH}$ with varying redox states of $\mathrm{FeS}$ (e.g. unaerated, partially aerated or thoroughly aerated FeS). In this manner, beam-induced redox transformation could be evaluated as a function of the redox state of $\mathrm{FeS}$ as well as the solid-phase As speciation.

\section{Materials and methods}

\subsection{Sample preparation}

Different types of As-reacted FeS samples were subjected to As $K$-edge XAS measurements. Poorly crystallized FeS was synthesized by mixing $2.0 \mathrm{~L}$ of $0.57 M \mathrm{FeCl}_{2}$ solution with 1.2 $\mathrm{L}$ of $1.1 \mathrm{M} \mathrm{Na}_{2} \mathrm{~S}$ solution inside an anaerobic glovebox with the atmospheric composition of $4 \% \mathrm{H}_{2} / 96 \% \mathrm{~N}_{2}$ (Butler $\&$ Hayes, 1998). The precipitated particles were allowed to age for three days before being rinsed with distilled water to remove residual salts. Subsequently, the resultant particles were freeze-dried and kept in an air-tight vial. As indicated by broad reflection peaks (see Fig. S1A of the supporting information), this phase was poorly crystalline mackinawite.

Sample preparation was conducted inside the glovebox, and de-oxygenated distilled water was used, unless otherwise mentioned. Aqueous FeS suspensions were reacted with either $\mathrm{As}(\mathrm{III})$ or $\mathrm{As}(\mathrm{V})$ solutions for three days to obtain the As-to-FeS concentration ratios in Table 1. Buffer solutions of $0.1 M$ acetate, 3-( $N$-morpholino)propanesulfonate (MOPS), and 2-( $N$-cyclohexylamino)ethanesulfonate (CHES) were used to adjust the $\mathrm{pH}$ of the suspensions to 5,7 and 9 , respectively. Following the reaction period, portions of the resultant suspensions were removed from the glovebox to produce 'partially aerated samples' as a function of aeration time under the ambient atmosphere. At pre-determined times, aliquots of the oxidized FeS suspensions were collected and immediately transferred to the glovebox. Subsequently, they were filtered to prepare the partially oxidized samples. In parallel, the remaining FeS suspensions in the glovebox were filtered to have 'unaerated samples'. In a separate experiment, an FeS suspension without As addition was aerated for six months to produce the completely oxidized product of FeS. After being freeze-dried, the 'thoroughly aerated samples' were blended in powder forms with As reference compounds including $\mathrm{As}(0), \mathrm{As}_{2}^{\mathrm{III}} \mathrm{S}_{3}$ and $\mathrm{NaAs}^{\mathrm{III}} \mathrm{O}_{2}$ at a mass ratio of $1: 9$ inside the glovebox. In order to facilitate electron transfer between the powder mixtures during XAS measurements, several drops of distilled anoxic water were applied to make wet pastes. For XAS measurements, As-reacted samples as wet pastes were placed as a thin layer between two layers of Kapton tape inside the glovebox. Then, the XAS samples were stored in air-tight, crimp-sealed serum vials and transferred to Pohang Accelerator Laboratory (PAL) in Korea for As $K$ edge XAS experiments. To obtain mineralogical compositions, As sorption samples after being dried were analyzed by either conventional laboratory-based X-ray diffraction (XRD) or synchrotron XRD at the 9B beamline at PAL, with the results given in Figs. S1 and S2 in the supporting information.

\subsection{XAS measurements and analyses}

A total of 22 samples were subjected to As $K$-edge XAS measurements to assess the beam-induced redox transformation. Table 1 summarizes sample preparation conditions, sample chamber mood, and the occurrence of beam-induced transformation. The XAS data were collected at the beamline 8C (a focused beam with an undulator type) at PAL. A double-crystal $\mathrm{Si}(111)$ monochromator was used to produce a monochromatic beam, with $30 \%$ detuning to remove higherorder harmonics. The photon flux and beam size at the sample position were $2 \times 10^{12}$ photons $^{-1}$ and $0.66 \mathrm{~mm}^{2}(0.22 \mathrm{~mm} \times$ 
Table 1

Summary of sample preparation conditions, sample chamber mood and results of beam-induced redox transformation.

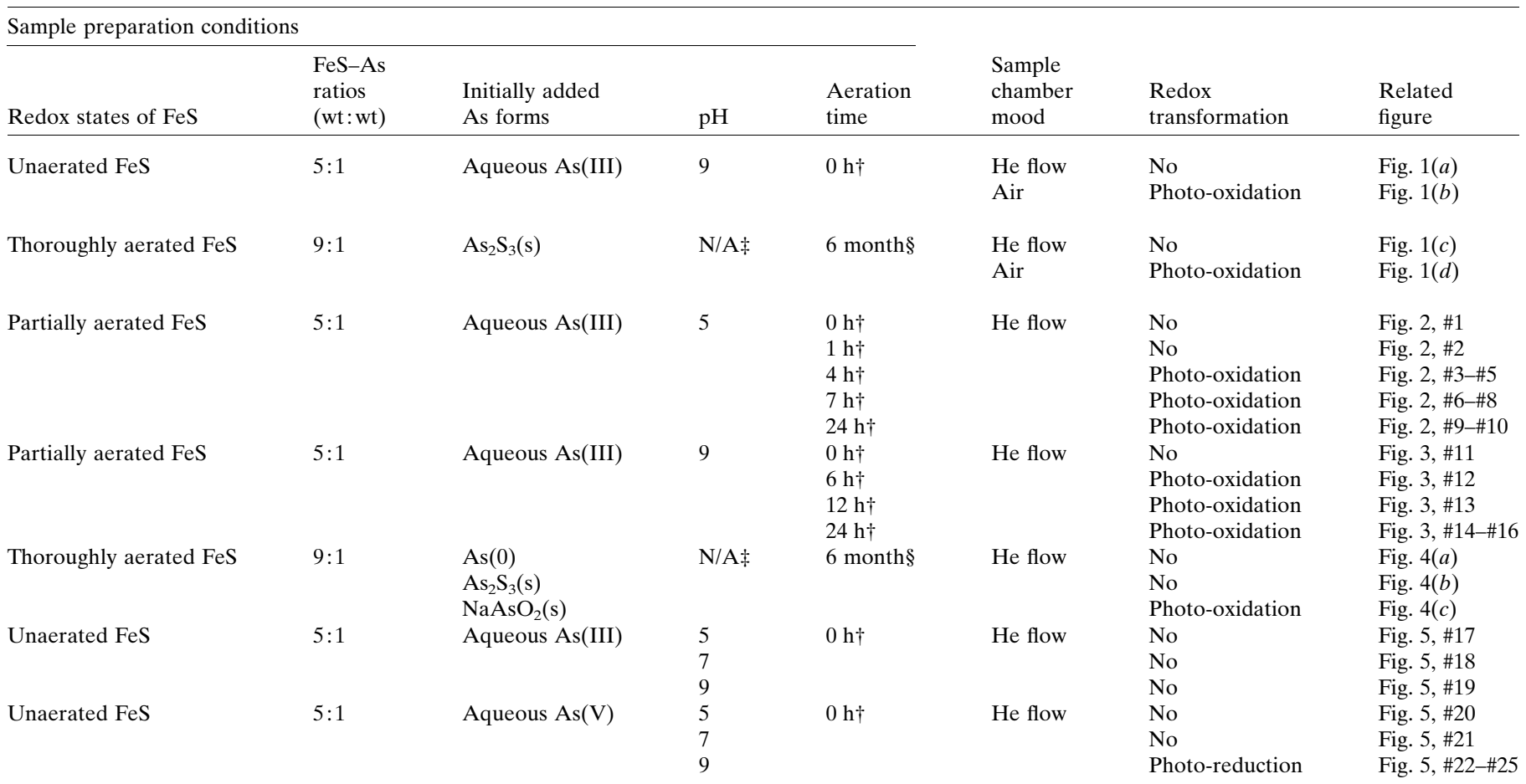

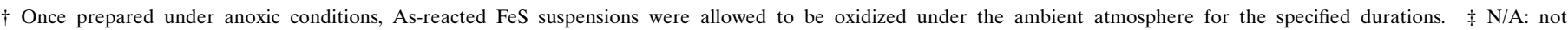
applicable. \& FeS suspensions without As amendment were first oxidized, and then the oxidation products in powder forms were mechanically mixed with As reference compounds.

$3 \mathrm{~mm}$ ), respectively, to yield the beam intensity of $3.0 \times 10^{12}$ photons $\mathrm{mm}^{-2} \mathrm{~s}^{-1}$. Multiple scans of As $K$-edge XAS data were obtained at room temperature using both transmission and fluorescence modes. The completion of photocatalytic redox transformation could not be taken into account in determining the number of scans since such transformation was not recognized until the data analyses. A single scan took $37 \mathrm{~min}$ for the energy range of about $1000 \mathrm{eV}$ (11667$12615 \mathrm{eV})$. To account for the energy shift, energy calibration was performed for each scan using a $\mathrm{Au}(0)$ foil ( $\mathrm{Au} L_{3}$-edge at $11919 \mathrm{eV}$ ) placed between the $\mathrm{I}_{1}$ and $\mathrm{I}_{2}$ ion chambers.

Using SixPack software (Webb, 2002), the As $K$-edge XAS spectra were subjected to both X-ray absorption near-edge structure (XANES) and extended X-ray absorption fine structure (EXAFS) analyses. The background X-ray absorbance was removed by a linear fit through the pre-edge region. Subsequently, XANES regions were isolated by normalizing the signal to the edge-jump height. From multiple XANES spectra of each sample, the absorption-edge energies were measured to determine the oxidation state of As and to detect the occurrence of its beam-induced redox transformation. Since an energy scan with a step size of $0.2 \mathrm{eV}$ was applied around the absorption edge, a shift of edge energies greater than $0.2 \mathrm{eV}$ among multiple scans was considered to be indicative of photocatalytic redox transformation. In addition, linear combination fitting (LCF) was performed using XANES spectra to determine the As speciation. Considering that two arsenic sulfides, $\mathrm{AsS}$ and $\mathrm{As}_{2} \mathrm{~S}_{3}$, had close absorptionedge energies and similar XANES shapes, these sulfide phases were not differentiated in the LCF analysis. Due to the unavailability of exact reference compounds, the XANES spectra of aqueous $\mathrm{As}(\mathrm{III})$ and $\mathrm{As}(\mathrm{V})$ were employed to represent those of surface-complexed As(III) and As(V), respectively. Indeed, this approach generally led to a good fitting since XANES spectra commonly show a linear relation between the edge energy and the formal oxidation state (Wong et al., 1984). Although the absorption edge could also be affected by the nature of the ligands (Yin et al., 1995), it was a good indicator to determine the oxidation state of As in our simple system. The details of the LCF results can be found in the supporting information (Table S1). The EXAFS spectra were also analyzed using SixPack software. The Fourier transforms (FTs) of $k^{3}$-weighted EXAFS spectra were fitted with the As-O and/or As-S paths regenerated by FEFF8 (Ankudinov et al., 1998). In this analysis, only the first shells were fitted given that high $k$ regions were not convincing due to the low signal-to-noise ratios.

\section{Results and discussion}

\subsection{Beam-induced oxidation}

3.1.1. Atmospheric $\mathrm{O}_{2}$ as an oxidizing agent. During XAS measurements of redox-sensitive samples, a sample chamber under an inert gas flow or vacuum is recommended to prevent photo-oxidation by the atmospheric $\mathrm{O}_{2}$. Fig. 1 shows the As $K$ edge XANES spectra resulting from a series of consecutive measurements on the same spot of As-reacted samples. As 
shown in Fig. 1(a), the unaerated As(III)-reacted FeS sample in a He flow chamber did not exhibit noticeable changes in the XANES spectra during the first three scans. On the other hand, as seen in Fig. 1(b), the sample exposed to the ambient air during XAS measurements showed significant changes in its XANES spectra. The peak at the position of the arsenic sulfide white-line decreased in intensity with the number of scans, but the peak at the aqueous $\mathrm{As}(\mathrm{V})$ white-line increased, indicating the photocatalytic oxidation of $\mathrm{As}(\mathrm{III})$ to $\mathrm{As}(\mathrm{V})$. The As(III) species formed in the unaerated As(III)-reacted FeS samples at $\mathrm{pH} 9$, although its XANES white-line energy matched that of arsenic sulfide, had been regarded as surface complexed thioarsenite (Planer-Friedrich et al., 2015; Suess et al., 2009). These results point to the importance of $\mathrm{O}_{2}$ exclusion during XAS measurements to prevent the photo-oxidation of As.

The occurrence of the photo-oxidation was further examined under similar conditions when Fe(III) minerals were present as the potential oxidizing agents. In Figs. 1(c) and 1(d), a mixture of the thoroughly aerated FeS (a composite of goethite, hematite, magnetite and elemental sulfur; see Fig. S1B) with $\mathrm{As}_{2} \mathrm{~S}_{3}$ was subjected to X-ray beam irradiation with and without $\mathrm{O}_{2}$ exclusion. Similar to the results depicted in Figs. 1(a) and 1(b), the photo-oxidation of As during XAS measurements was evident only under the ambient air, even though this sample contained $\mathrm{Fe}(\mathrm{III})$ minerals. Thus, it can be inferred that the atmospheric $\mathrm{O}_{2}$ is a more effective oxidizing agent than $\mathrm{Fe}(\mathrm{III})$ (oxyhydr)oxides. Taken together, the
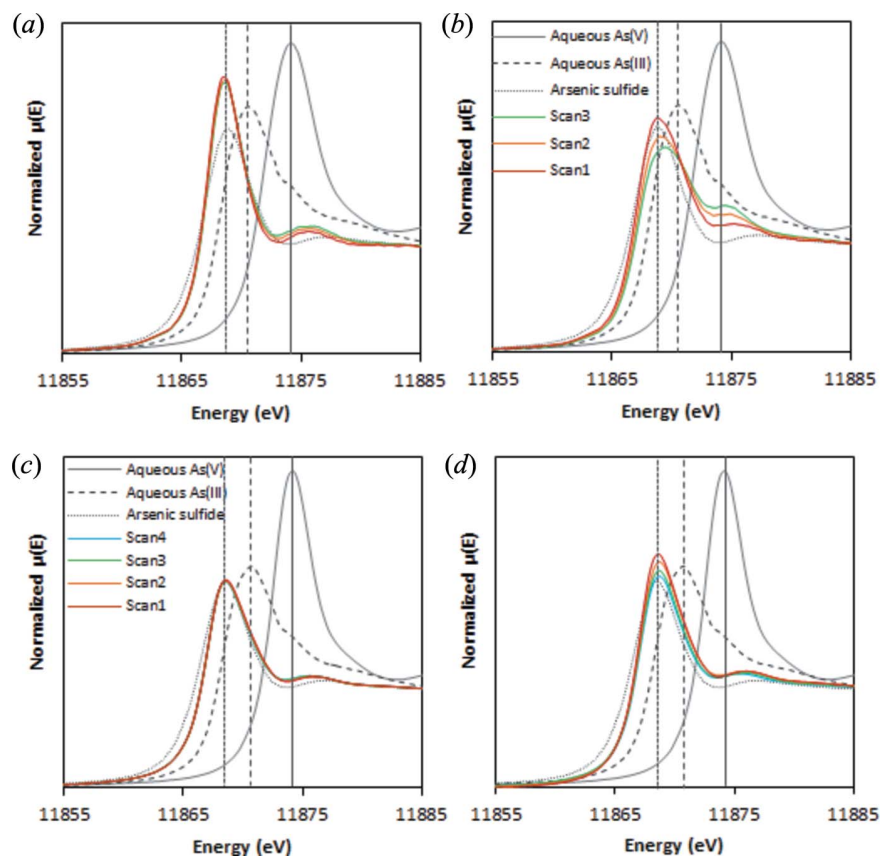

Figure 1

As $K$-edge XANES spectra of (a) unaerated As(III)-reacted FeS at $\mathrm{pH} 9$ using a He flow sample chamber, $(b)$ unaerated $\mathrm{As}(\mathrm{III})$-reacted $\mathrm{FeS}$ at pH 9 without exclusion of the atmospheric $\mathrm{O}_{2},(c)$ a mixture of the thoroughly aerated $\mathrm{FeS}$ and $\mathrm{As}_{2} \mathrm{~S}_{3}$ using a He flow sample chamber, and (d) a mixture of the thoroughly aerated $\mathrm{FeS}$ and $\mathrm{As}_{2} \mathrm{~S}_{3}$ without exclusion of the atmospheric $\mathrm{O}_{2}$. The beam exposure time was about $37 \mathrm{~min}$ per scan in a series of multiple scans. exclusion of $\mathrm{O}_{2}$ during XAS experiments is necessary to prevent the samples containing reduced As species from undergoing photo-oxidation.

3.1.2. FeS oxidation products as oxidizing agents. As discussed above, the atmospheric $\mathrm{O}_{2}$ can mediate the photooxidation of reduced As species. Yet, the photo-oxidation was also encountered in some of the partially aerated $\mathrm{FeS}$ samples even with complete $\mathrm{O}_{2}$ exclusion. Figs. 2 and 3 show the XANES spectra and corresponding LCF results for the partially aerated $\mathrm{As}(\mathrm{III})$-reacted samples at $\mathrm{pH} 5$ and 9, respectively. Given the varying aeration time, these samples were expected to be at different redox states. During the early aeration period, the formation of $\mathrm{FeS}$ oxidation products was not shown by XRD analysis likely due to their low crystallinity (see Fig. S2 in the supporting information). Nonetheless, as shown in Fig. S3, the increasing oxidation-reduction potentials with the aeration time clearly illustrated the occurrence of FeS oxidation from the beginning.

As shown in Fig. 2, the unaerated sample at $\mathrm{pH} 5$ (spectrum 1) did not undergo photocatalytic oxidation. Also, the $1 \mathrm{~h}$ aeration of $\mathrm{As}(\mathrm{III})$-reacted $\mathrm{FeS}$ sample at $\mathrm{pH} 5$ (spectrum 2) did not lead to noticeable changes among successive XANES spectra. However, as indicated by the increasing $\mathrm{As}(\mathrm{V})$ fraction with the number of scans in LCF analysis, the pH 5 samples subjected to prolonged aeration (spectra 3-10) underwent the photocatalytic oxidation during XAS (a)

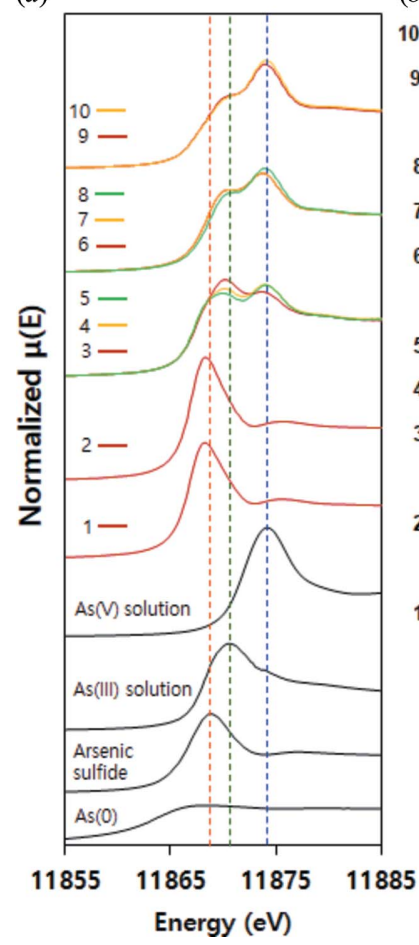

(b)

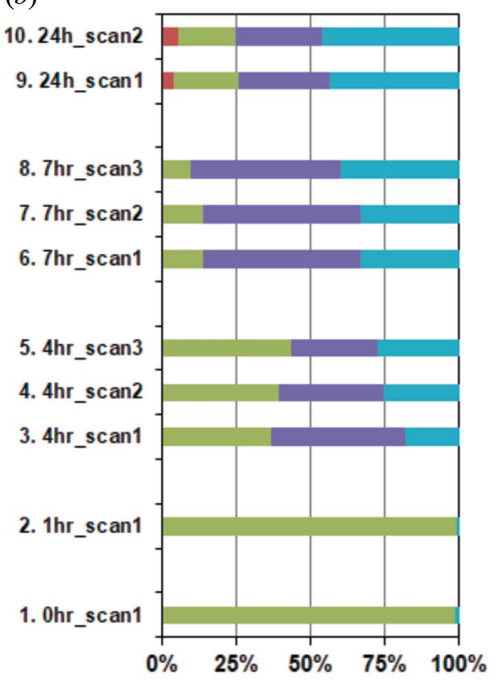

As species composition (\%)

\begin{tabular}{|c|c|}
\hline $\begin{array}{l}\text { XANES, EXAFS indicator } \\
\text { Arsenic sulfide } \\
\text { As(III) solution } \\
\text { As(V) solution }\end{array}$ & $\begin{array}{l}\text { LCF references } \\
\text { — As(0) } \\
\text { " Arsenic sulfide } \\
\text { As(III) solution } \\
\| \text { As(V) solution }\end{array}$ \\
\hline
\end{tabular}

Figure 2

(a) As $K$-edge XANES spectra and (b) the corresponding LCF results for the partially aerated $\mathrm{As}(\mathrm{III})$-reacted $\mathrm{FeS}$ at $\mathrm{pH} 5$ using a He flow sample chamber. The samples that did not undergo redox transformation are represented by single spectra, and those undergoing the photo-oxidation are represented by a series of successive scans. The beam exposure time was about 37 min per scan in a series of multiple scans. 
measurements. A longer aeration of the $\mathrm{pH} 5$ samples would lead to the greater formation of $\mathrm{FeS}$ oxidation products (e.g. ferrihydrite and elemental sulfur), which may have accelerated the beam-induced oxidation. At $\mathrm{pH} 9$, the photooxidation did not occur in both unaerated samples and up to $12 \mathrm{~h}$-aerated samples (spectra 11-13 in Fig. 3). In contrast, it is apparent that the $24 \mathrm{~h}$-aerated sample (spectra 14-16 in Fig. 3) underwent the photo-oxidation by which surface-complexed As(III) was transformed into surface-complexed $\mathrm{As}(\mathrm{V})$.

When preparing the partially aerated samples, the dissolved $\mathrm{O}_{2}$ introduced during the aeration step should be completely removed. Also, given the $\mathrm{O}_{2}$ exclusion in a He flow sample chamber, the oxidation products of $\mathrm{FeS}$ (e.g. ferrihydrite and elemental sulfur) were likely responsible for the observed photo-oxidation in the present study. Previously, both Fe(III) (oxyhydr)oxides and intermediate sulfurs (e.g. polysulfide and elemental sulfur) were found to trigger the oxidation of $\mathrm{As}(\mathrm{III})$ to $\mathrm{As}(\mathrm{V})$ under ambient conditions even in the absence of high energy beam radiation (Helz \& Tossell, 2008; Pozdnyakov et al., 2016). Taken together, the photo-oxidation of reduced As species may proceed under anoxic conditions, and the exclusion of $\mathrm{O}_{2}$ in an XAS sample chamber is not sufficient enough to prevent the photo-oxidation.

While the photo-oxidation occurred in the $4 \mathrm{~h}$-aerated samples at $\mathrm{pH} 5$ (see Fig. 2), no such change was noted in the 12 h-aerated sample at $\mathrm{pH} 9$ (see Fig. 3). In Fig. S2 of the

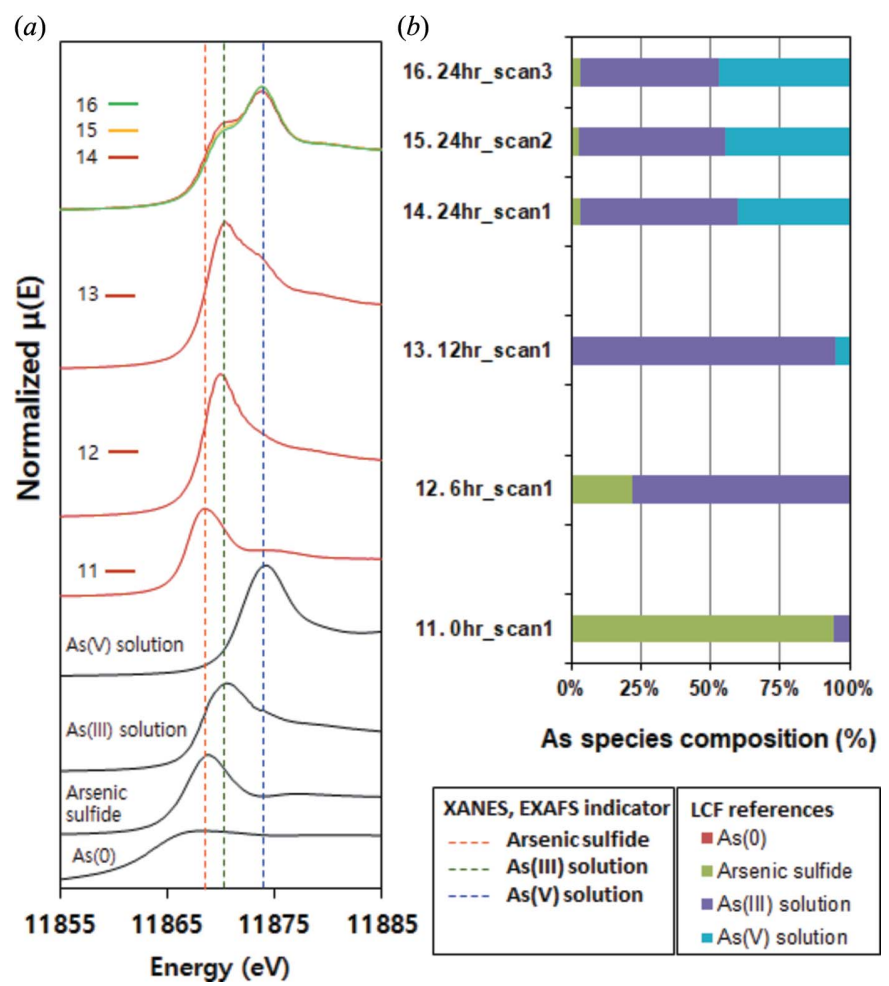

Figure 3

(a) As $K$-edge XANES spectra and (b) the corresponding LCF results for the partially aerated $\mathrm{As}(\mathrm{III})$-reacted $\mathrm{FeS}$ at $\mathrm{pH} 9$ using a He flow sample chamber. The samples that did not undergo redox transformation are represented by single spectra, and those undergoing the photo-oxidation are represented by a series of successive scans. The beam exposure time was about 37 min per scan in a series of multiple scans. supporting information, the reflection peaks of FeS during the aeration disappeared earlier at $\mathrm{pH} 5$ than at $\mathrm{pH} 9$, indicating the faster oxidation of $\mathrm{FeS}$ at $\mathrm{pH} 5$. In agreement with this finding, Chiriţă \& Schlegel (2012) have proposed that the oxidative dissolution of FeS under acidic conditions is expedited by both oxygen and proton. Thus, the prevalence of the photo-oxidation in the acidic samples further supports the involvement of FeS oxidation products as the oxidizing agents.

3.1.3. Susceptibility of As species to photo-oxidation. To compare the stability of different As species against the photooxidation, the thoroughly aerated product of $\mathrm{FeS}$ (a composite of goethite, hematite, magnetite and elemental sulfur) in powder forms was mechanically mixed with $\mathrm{As}(0), \mathrm{As}_{2} \mathrm{~S}_{3}$ or $\mathrm{NaAsO}_{2}$, and then a few drops of deoxygenated water was applied to the resulting mixtures to prepare wet pastes. A series of As $K$-edge XAS spectra were collected under a $\mathrm{He}$ flow for these mixtures. In Fig. 4, the mixtures with As( $(0)$ and $\mathrm{As}_{2} \mathrm{~S}_{3}$ showed no appreciable changes in their successive XANES spectra, indicating that neither of these As phases were photocatalytically oxidized by $\mathrm{Fe}$ (III) (oxyhydr)oxides under our experimental conditions (e.g. beam intensity and beam exposure time). However, as mentioned above, arsenic sulfide was prone to photo-oxidation by the atmospheric $\mathrm{O}_{2}$, a stronger oxidant (see Fig. 1d). In contrast to the stability of $\mathrm{As}(0)$ and $\mathrm{As}_{2} \mathrm{~S}_{3}$ against the photo-oxidation, the mixture with $\mathrm{NaAsO}_{2}$ exhibited noticeable changes in its XANES spectra; the intensity at the aqueous As(III) white-line decreased with the number of scans. In a wet slurry, a portion of $\mathrm{NaAsO}_{2}$ would form surface complexes with $\mathrm{Fe}$ (III) (oxyhydr)oxides. Thus, either $\mathrm{NaAsO}_{2}$ salt, surface-complexed As(III) or both would be photocatalytically oxidized by Fe(III) (oxyhydr)-
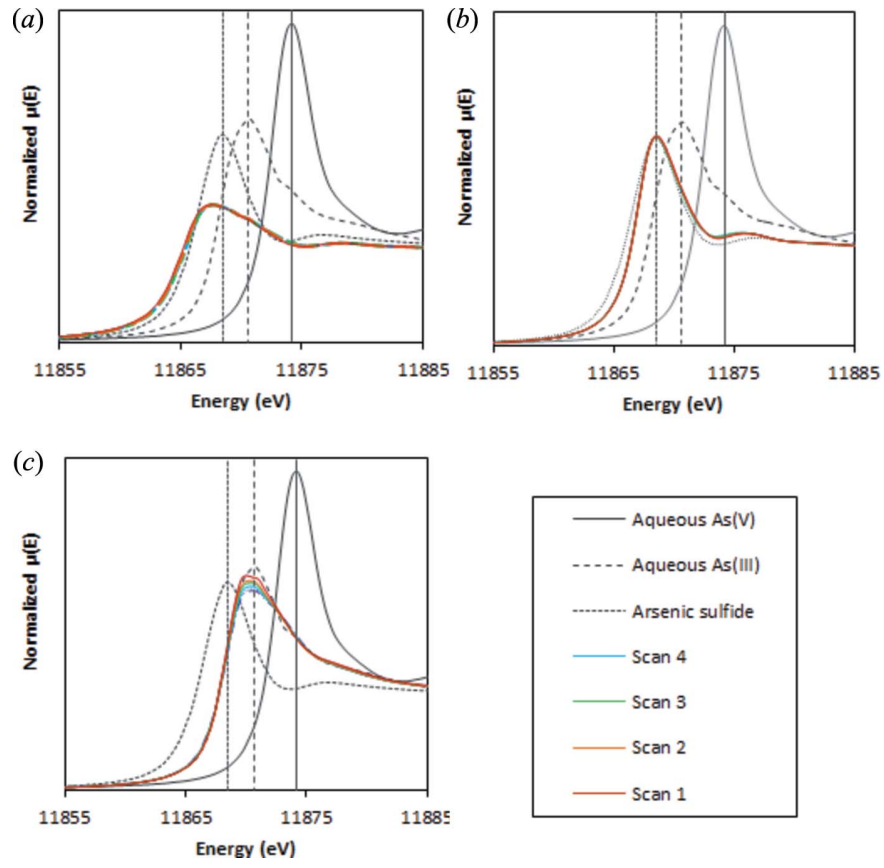

Figure 4

As $K$-edge XANES spectra for the mixture of the thoroughly aerated FeS with (a) $\mathrm{As}(0),(b) \mathrm{As}_{2} \mathrm{~S}_{3}$ and (c) $\mathrm{NaAsO}_{2}$ using a He flow sample chamber. 
oxides. Given the greater solubility, ionic $\mathrm{NaAsO}_{2}$ has a lower lattice energy than metallic $\mathrm{As}(0)$ and covalent $\mathrm{As}_{2} \mathrm{~S}_{3}$, thus making the former more susceptible to the photo-oxidation. In addition, surface complexation usually involves a smaller amount of formation energy. Consistently, the photo-oxidation of arsenic during XAS measurements has been mostly reported for surface complexation of $\mathrm{As}$ (III) with $\mathrm{Fe}(\mathrm{III})$ (oxyhydr)oxides (Bostick \& Fendorf, 2003; Charlet et al., 2011). Taken together, surface-complexed As(III) or ionic salts is more susceptible to the photo-oxidation than $\mathrm{As}(0)$ and arsenic sulfide.

\subsection{Beam-induced reduction}

In Fig. 5, As $K$-edge XANES and EXAFS spectra collected using a He flow sample chamber are shown for the unaerated As(III)- and As(V)-reacted FeS samples at different $\mathrm{pH}$. The absorption-edge energies and EXAFS fitting results of these samples are summarized in Table 2. By comparing both XANES and EXAFS spectra, an $\mathrm{As}_{2} \mathrm{~S}_{3}$-like structure was found to be mainly responsible for As(III) uptake by FeS, consistent with Han et al. (2018). During XAS measurements, no appreciable changes were noted for the XANES and EXAFS spectra of As(III)-reacted FeS samples. Thus, as in the case of the photo-oxidation, arsenic sulfide is not sensitive to the photo-reduction.

In the case of $\mathrm{As}(\mathrm{V})$-reacted FeS samples, the dissimilarities in their XANES and EXAFS spectra suggest that As(V) sorption by FeS is strongly dependent on pH. In Fig. 5(a), the XANES spectra of As(V)-reacted FeS samples are characterized by two distinct white-line peaks (11867.7 and $11872.0 \mathrm{eV}$ of adsorption-edge energies: see Table 2) which match those of arsenic sulfide and aqueous As(V). Likewise, the FTs of As(V)-reacted FeS samples reveal the presence of two distinct subshells at $2.23-2.26 \AA$ and $1.66-1.69 \AA$. Furthermore, by comparing the LCF results of spectra 20-22 in Fig. 5(b), surface-complexed As(V) became more important compared with reduced As species [e.g. arsenic sulfide and surface-complexed As(III)] with the increasing $\mathrm{pH}$, implying that $\mathrm{As}(\mathrm{V})$ is not readily reduced at basic $\mathrm{pH}$ in the absence of photocatalysis. Indeed, Niazi \& Burton (2016) reported that more $\mathrm{As}(\mathrm{V})$ was reduced to $\mathrm{As}(\mathrm{III})$ by reaction with $\mathrm{FeS}$ at $\mathrm{pH} 6$ than $\mathrm{pH} 9$ due to the greater availability of dissolved $\mathrm{S}^{2-}$ at the lower $\mathrm{pH}$. In this regard, the higher solubility of $\mathrm{FeS}$ in the $\mathrm{pH} 5 \mathrm{As}(\mathrm{V})$-reacted sample could explain the greater proportion of arsenic sulfide and surfacecomplexed As(III) compared with that in the pH 9 As(V)reacted sample.

In $\mathrm{As}(\mathrm{V})$-reacted FeS samples, the beam-induced reduction was not observed at $\mathrm{pH} 5$ and 7 but at $\mathrm{pH}$ 9. This could be attributable to the different solid-phase As speciation with $\mathrm{pH}$. As previously mentioned, arsenic sulfide was not prone to the photo-reduction during XAS measurement. In contrast, surface-complexed As(V), the more labile species, would readily undergo the photo-reduction. Consistent with this postulation, the proportion of $\mathrm{As}(\mathrm{V})$ in the $\mathrm{pH} 9 \mathrm{As}(\mathrm{V})$ reacted sample was found to decrease with the number of scans, along with the increasing fraction of arsenic sulfide [compare the LCF results of spectra 22-25 in Fig. 5(b)]. Also, such a trend can be readily gleaned from the consecutive EXAFS spectra and FTs of the $\mathrm{pH} 9$ As(V)-reacted sample [see Figs. 5(c) and 5(d)]. Furthermore, as shown in Table 2, the coordination number of the As-O subshell in this sample decreased from 2.84 to 1.16 with the number of scans, while that of the As-S shell increased from 1.25 to 2.08. Thus, the $\mathrm{As}(\mathrm{V})$ reduction by $\mathrm{FeS}$, although kinetically limited at basic $\mathrm{pH}$, can be accelerated upon beam exposure during XAS measurements.

\section{Conclusions}

This study demonstrated that the beam-induced redox transformation of As during XAS measurements is closely related to sample properties. Both the availability of electron acceptors or donors and the solid-phase As speciation were shown to be critical in determining the redox stability of As against the photocatalytic transformation. Under our experimental conditions, surface-complexed As appeared to be more vulnerable to the photocatalytic transformation than discrete phases including $\operatorname{As}(0)$ and arsenic sulfide. Given that XAS collection conditions including beam intensity and collection temperature are also important in determining the beaminduced redox transformation, our future study will address such aspects. Nonetheless, when analyzing the sample containing As species vulnerable to the photocatalytic transformation, it may be helpful to collect XAS spectra with strict $\mathrm{O}_{2}$ exclusion at cryogenic temperature. Also, it is recommended to employ quick-scanning methods such as Q-XAS to reduce beam exposure.

\section{Acknowledgements}

XAS and XRD experiments were conducted at beamlines $8 \mathrm{C}$ and 9B, respectively, at the Pohang Accelerator Laboratory (PAL) in Korea. Experimental works at the PAL were supported in part by the Ministry of Educational Science and Technology of the Korean Government and Pohang University of Science and Technology (POSTECH).

\section{Funding information}

Funding for this research was provided by: Basic Research Project of the Korea Institute of Geoscience and Mineral Resources (Project 18-3413); Basic Science Research Program through the National Research Foundation of Korea (Project NRF-2016R1D1A1B04931643).

\section{References}

Alessi, D. S., Uster, B., Borca, C. N., Grolimund, D. \& BernierLatmani, R. (2013). J. Synchrotron Rad. 20, 197-199.

Ankudinov, A., Ravel, B., Rehr, J. J. \& Conradson, S. D. (1998). Phys. Rev. B, 58, 7565-7576.

Bhandari, N., Reeder, R. J. \& Strongin, D. R. (2011). Environ. Sci. Technol. 45, 2783-2789.

Bhandari, N., Reeder, R. J. \& Strongin, D. R. (2012). Environ. Sci. Technol. 46, 8044-8051. 
Table 2

As $K$-edge absorption-edge energies and EXAFS fitting results of As reference compounds as well as unaerated As(III)- and As(V)-reacted FeS samples in Fig. 5.

The EXAFS fitting was performed on the first coordination shells.

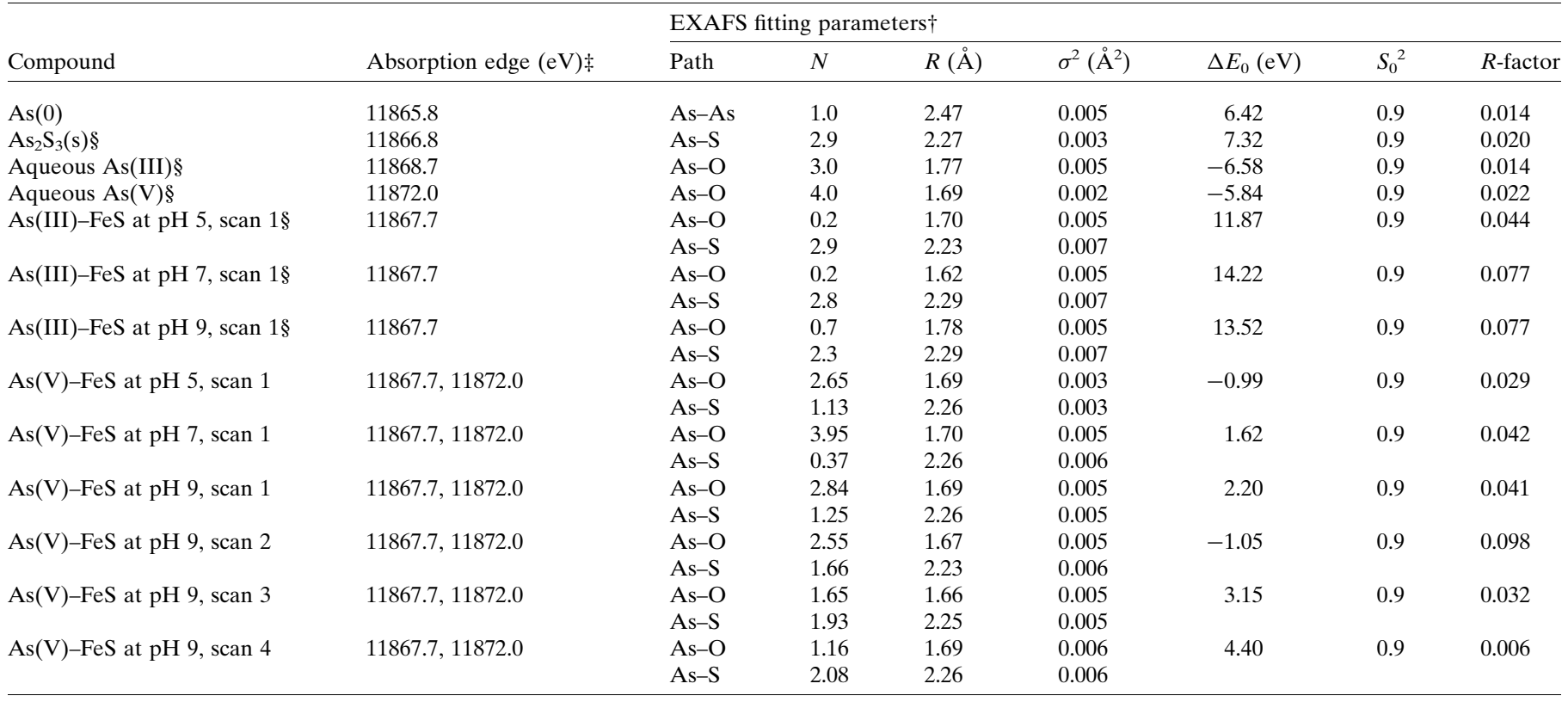

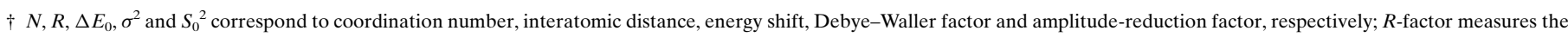

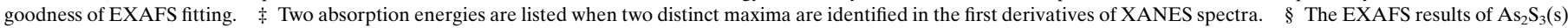
aqueous As(III), aqueous $\mathrm{As}(\mathrm{V})$ and unaerated As(III)-reacted FeS samples are adopted from Han et al. (2018).

(a)

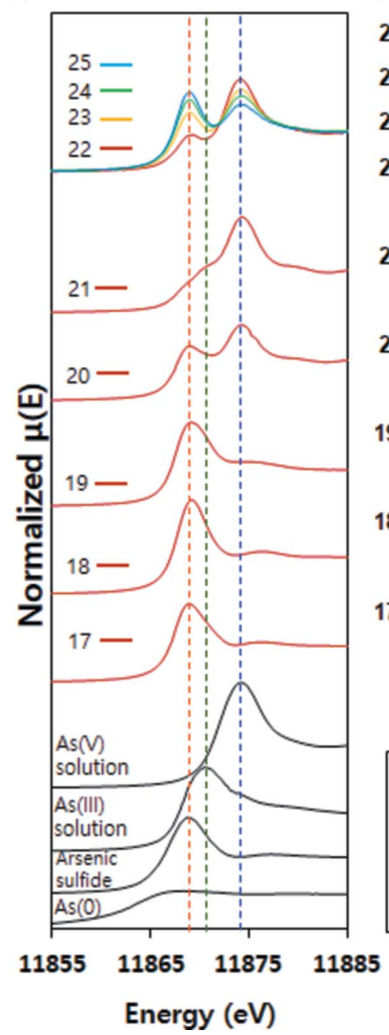

(b)

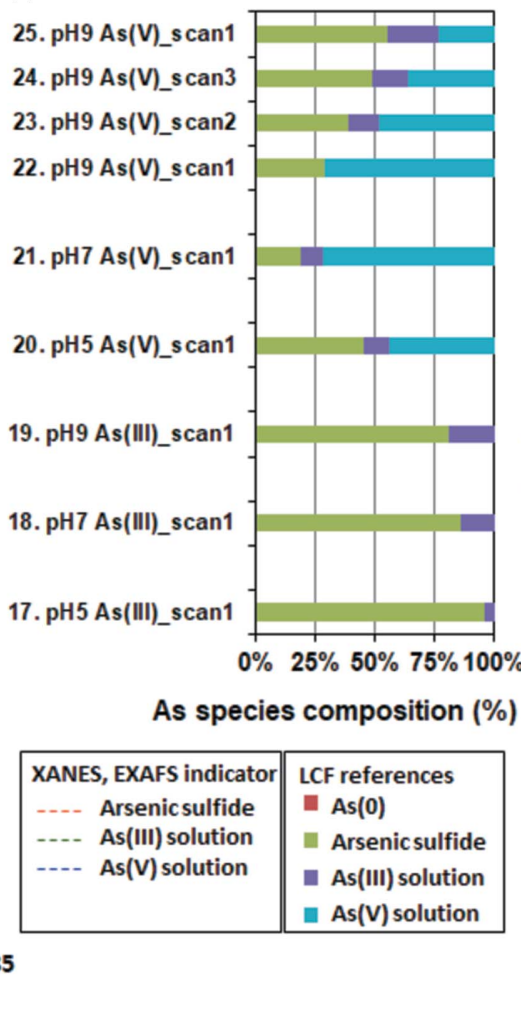

(c)

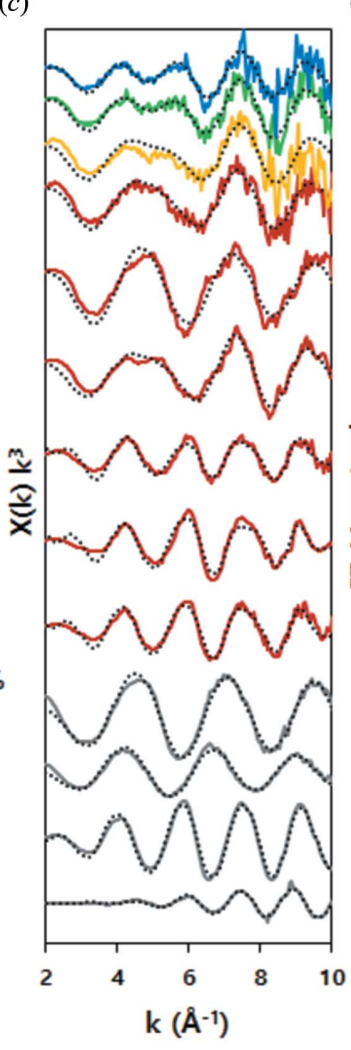

(d)

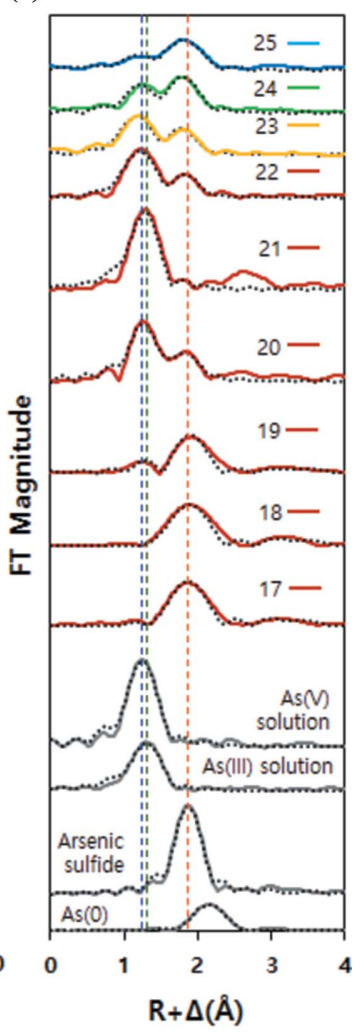

Figure 5

(a) As $K$-edge XANES spectra, (b) LCF results of XANES spectra, $(c) k^{3}$-weighted EXAFS spectra (solid lines) with the fitting results (dotted lines) and (d) the corresponding FTs (solid lines) with the fitting results (dotted lines) for the unaerated As(III)- and As(V)-reacted FeS at pH 5, 7 and 9 using a He flow sample chamber. The samples that did not undergo redox transformation are represented by single spectra, and those undergoing the photoreduction are represented by a series of successive scans. The beam exposure time was about 37 min per scan in a series of multiple scans. 
Bostick, B. C. \& Fendorf, S. (2003). Geochim. Cosmochim. Acta, 67, 909-921.

Bostick, B. C., Fendorf, S. \& Manning, B. A. (2003). Geochim. Cosmochim. Acta, 67, 895-907.

Butler, E. C. \& Hayes, K. F. (1998). Environ. Sci. Technol. 32, $1276-$ 1284.

Charlet, L., Morin, G., Rose, J., Wang, Y., Auffan, M., Burnol, A. \& Fernandez-Martinez, A. (2011). C. R. Geosci. 343, 123-139.

Chiriţă, P. \& Schlegel, M. L. (2012). Chem. Geol. 334, 131-138.

Foster, A. L. \& Kim, C. S. (2014). Arsenic Environmental Geochemistry, Mineralogy, and Microbiology, edited by R. J. Bowell, C. N. Alpers, H. E. Jamieson, D. K. Nordstrom \& J. Majzlan, ch. 5. Chantilly, VA: Mineralogical Society of America.

George, G. N., Pickering, I. J., Pushie, M. J., Nienaber, K., Hackett, M. J., Ascone, I., Hedman, B., Hodgson, K. O., Aitken, J. B., Levina, A., Glover, C. \& Lay, P. A. (2012). J. Synchrotron Rad. 19, 875-886.

Ginder-Vogel, M., Landrot, G., Fischel, J. S. \& Sparks, D. L. (2009). Proc. Natl Acad. Sci. USA, 106, 16124-16128.

Gruenert, W., Hayes, N. W., Joyner, R. W., Shpiro, E. S., Siddiqui, M. R. H. \& Baeva, G. N. (1994). J. Phys. Chem. 98, 10832-10846.

Han, Y.-S., Seong, H. J., Chon, C.-M., Park, J. H., Nam, I.-H., Yoo, K. \& Ahn, J. S. (2018). Chemosphere, 195, 762-770.

Helz, G. R. \& Tossell, J. A. (2008). Geochim. Cosmochim. Acta, 72, 4457-4468.

Kempson, I. M., Henry, D. \& Francis, J. (2009). J. Synchrotron Rad. 16, 422-427.

Keune, K., Mass, J., Meirer, F., Pottasch, C., van Loon, A., Hull, A., Church, J., Pouyet, E., Cotte, M. \& Mehta, A. (2015). J. Anal. At. Spectrom. 30, 813-827.

Lee, W. C., Choi, S. H., Cho, H. G. \& Kim, S.-O. (2011). J. Mineral. Soc. Korea, 24, 73-82.

Lombi, E., Scheckel, K. G. \& Kempson, I. M. (2011). Environ. Exp. Bot. 72, 3-17.
Luo, H. W., Chen, J. J., Sheng, G. P., Su, J. H., Wei, S. Q. \& Yu, H. Q. (2014). Sci. Rep. 4, 7078.

Mavrogenes, J. A., Berry, A. J., Newville, M. \& Sutton, S. R. (2002). Am. Mineral. 87, 1360-1364.

Morin, G., Ona-Nguema, G., Wang, Y. H., Menguy, N., Juillot, F., Proux, O., Guyot, F., Calas, G. \& Brown, G. E. (2008). Environ. Sci. Technol. 42, 2361-2366.

Niazi, N. K. \& Burton, E. D. (2016). Environ. Pollut. 218, 111-117.

Ohkubo, Y., Nakagawa, T., Seino, S., Kugai, J., Yamamoto, T. A., Nitani, H. \& Niwa, Y. (2014). J. Synchrotron Rad. 21, 1148-1152.

Ona-Nguema, G., Morin, G., Juillot, F., Calas, G. \& Brown, G. E. (2005). Environ. Sci. Technol. 39, 9147-9155.

Planer-Friedrich, B., Härtig, C., Lohmayer, R., Suess, E., McCann, S. H. \& Oremland, R. (2015). Environ. Sci. Technol. 49, 65546563.

Pozdnyakov, I. P., Ding, W., Xu, J., Chen, L., Wu, F., Grivin, V. P. \& Plyusnin, V. F. (2016). Photochem. Photobiol. Sci. 15, 431-439.

Smith, E., Kempson, I., Juhasz, A. L., Weber, J., Skinner, W. M. \& Gräfe, M. (2009). Chemosphere, 76, 529-535.

Su, Y., Brown, H. M., Li, G. S., Zhou, X. D., Amonette, J. E., Fulton, J. L., Camaioni, D. M. \& Zhang, Z. C. (2011). Appl. Catal. Gen. 391, 436-442.

Suess, E., Scheinost, A. C., Bostick, B. C., Merkel, B. J., Wallschlaeger, D. \& Planer-Friedrich, B. (2009). Anal. Chem. 81, 8318-8326.

Webb, S. M. (2002). Sam's interface for XAS package (SixPACK), Menlo Park, CA, USA.

Wong, J., Lytle, F. W., Messmer, R. P. \& Maylotte, D. H. (1984). Phys. Rev. B, 30, 5596-5610.

Yang, J. J., Regier, T., Dynes, J. J., Wang, J., Shi, J. Y., Peak, D., Zhao, Y. D., Hu, T. D., Chen, Y. X. \& Tse, J. S. (2011). Anal. Chem. 83, 7856-7862.

Yin, Z. F., Kasrai, M., Bancroft, G. M., Tan, K. H. \& Feng, X. H. (1995). Phys. Rev. B, 51, 742-750. 